\title{
ATRAVÉS DA TOLERÂNCIA E DO RESPEITO À DIVERSIDADE: UMA EDUCAÇÃO PARA REEDUCAR O HOMEM ATUAL
}

\section{THROUGH TOLERANCE AND RESPECT FOR DIVERSITY: AN EDUCATION TO REEDUCATE THE MAN OF TODAY}

\author{
Haleks Marques Silva ${ }^{1}$ \\ Walace Rodrigues ${ }^{2}$
}

\begin{abstract}
"Uma montanha não pode encontrar outra montanha, mas o homem facilmente encontra outro homem e aqui começa a solidariedade." (Schlesinger)
\end{abstract}

\begin{abstract}
Resumo: Este artigo nasce dos estudos e pesquisas sobre o conceito de cultura e identidade cultural na disciplina de "Tópicos I: Ensino e Valorização da Diversidade", do Programa de Pós-Graduação em Ensino de Língua e Literatura (PPGL-UFT). Este escrito objetiva refletir e analisar a identidade cultural pós-moderna tendo em vista uma perspectiva educacional metamórfica e solidária do ser humano. A metodologia utilizada foi teórica de cunho bibliográfica, feita através de análises de artigos, revistas, livros e em sites especializados no assunto. Os resultados mostram que a desfragmentação da identidade na pós-modernidade é apenas um começo de uma nova era e um novo modo de ser-no-mundo, sem certezas, sem portos fixos, sem verdades absolutas. A crise de identidade traz consigo também uma não aceitação do outro, do diferente, do diverso. Faz-se necessário, então, uma educação que seja capaz de suscitar nas mentes o respeito às diferenças e a busca sincera da própria verdade.
\end{abstract}

Palavras-chave: identidade cultural; tolerância; educação; solidariedade.

Abstract: This paper is born from studies and researches on the concept of culture and cultural identity in the disciplina of "Topics I: Teaching and Valuing Diversity", at the Postgraduate Program in Teaching Language and Literature (PPGL-UFT). This paper aims to reflect and analyze the postmodern cultural identity in view of a metamorphic educational perspective and the solidarity of the human being. The methodology used hereby was the theoretical one, of bibliographical nature, it was made through analyzes of articles, magazines, books and specialized

\footnotetext{
${ }^{1}$ Possui graduação em Filosofia pelo Instituto Santo Tomás de Aquino, ISTAIPUC Minas, Teologia pela Università Pontificia Salesiana de Roma, UPS, (Itália) e é Mestrando em Ensino de Língua e Literatura, pela Universidade Federal do Tocantins - UFT, campus de Araguaína. E-mail: halekshms@hotmail.com

${ }^{2}$ Professor Adjunto da Universidade Federal do Tocantins - UFT, campus de Araguaína. Doutor em Humanidades pela Universiteit Leiden (Países Baixos). Professor do Programa de Pós-Graduação em Ensino de Língua e Literatura (PPGL-UFT). Em estágio pós-doutoral na Universidade de Brasília (UnB). E-mail: walace@uft.edu.br
} 
websites in the subject. The results show that the defragmentation of identity in the postmodernity is only a beginning of a new era and a new way of being-in-the-world, without certainties, without fixed ports, without absolute truths. The crisis of identity also brings with it a non-acceptance of the other, of the different, of the diversity. It is necessary, then, an education that is capable of raising in the minds the respect towards the differents and a sincere search of one`s own truth.

Keywords: cultural identity; tolerance; education; solidarity

\section{Introdução}

Este artigo foi idealizado a partir das discussões nas aulas na disciplina de "Tópicos I: Ensino e Valorização da Diversidade”, do Programa de Pós-Graduação em Ensino de Língua e Literatura (PPGL) da Universidade Federal do Tocantins - UFT, campus de Araguaína. Esse escrito se colocou, também, como um dos pré-requisitos para a aprovação em tal disciplina. Ainda, esse artigo deveria ser enviado para uma revista nacional com relevância em uma das áreas das humanidades.

Este trabalho tem caráter exploratório e parte da utilização de bibliografia coerente com nossa discussão e de parte da bibliografia lida na referida disciplina. Buscamos, com este artigo, desenvolver algumas ideias sobre a identidade cultural e uma atual "crise de identidade" na pósmodernidade, suscitando algumas razões pelas quais a desfragmentação do sujeito pós-moderno poder levar à total desumanidade e intolerância em relação à diversidade.

Uma vez que o individualismo exacerbado se tornou filosofia de vida, paulatinamente as novas gerações têm perdido a capacidade de reconhecer o outro e perceber a sua real necessidade para a própria realização. Consequentemente, tudo o que é diferente, paradoxalmente, ao mesmo tempo atrai e acaba sendo alvo de preconceito e de intolerância.

Podemos, ainda, afirmar que, para superarmos as barreiras da individualidade, precisamos de propostas educacionais capazes de elucidar as mentes e os corações dos estudantes e precisamos reencantar a educação para reeducar o mundo, para que esse seja mais solidário, humano e amável.

\section{A multiplicidade de identidades culturais na pós-modernidade}

Um dos eixos centrais dos estudos culturais hodiernos é a questão da "identidade". O argumento nodal nada mais é de que "as velhas identidades, que por tanto tempo estabilizaram o mundo social, estão em declínio" (HALL, 2014, p. 9). Isso faz com que surjam novas identidades 
e causam, assim, uma desfragmentação do indivíduo moderno, até aqui visto como um sujeito unificado e com aparências de imutabilidade.

Todo esse processo é assim chamado de "crise de identidade". Essa crise é vista como parte de um quadro ainda maior de mudança. De acordo com Stuart Hall, tal crise "está deslocando as estruturas e processos centrais das sociedades modernas e abalando os quadros de referência que davam aos indivíduos uma ancoragem estável no mundo social” (Idem, p. 9).

Mas o que isso na prática quer significar e quais mudanças ocasionam? Essas transformações estão mudando a maneira como o próprio ser humano vê a si mesmo, o outro e o mundo. Uma vez que a crise de identidade está levando em colapso as representações culturais de classe, gênero, sexualidade, etnia, raça e nacionalidade que até pouco tempo forneciam uma localização sólida na sociedade.

Esses processos de mudança, em uma visão global, representam um processo de transformação tão fundamental e abrangente que somos impelidos a questionar toda a nossa concepção de cultura e nos faz repensar o que até agora acreditávamos saber, ser e crer. Por esta razão que Stuart Hall colocará a cultura no centro de suas pesquisas. Para ele a cultura é uma produção, e toda ruptura com alguma tradição ocasionará uma reviravolta no engendramento em torno da concepção de sujeito. Sendo assim, "paradoxalmente, nossas identidades culturais, em qualquer forma acabada estão à nossa frente. Estamos sempre em formação cultural. A cultura não é uma questão de ser, mas de se tornar” (HALL, 2009, p. 43). Isso faz com que as identidades, concebidas como estabelecidas e estáveis, estejam - por assim dizer - naufragando nas tempestades de uma diferenciação que se prolifera a cada dia, nas ciências, nas literaturas e nos mass media.

A propósito das metamorfoses da identidade, Hall distingue três compreensões bem diversas de identidade. A saber: 1. Sujeito do iluminismo, 2. Sujeito sociológico e 3. Sujeito pósmoderno. Vejamos, em grandes linhas, cada uma das suas concepções.

O sujeito do iluminismo "estava baseado numa concepção da pessoa humana como um indivíduo totalmente centrado, unificado (...), cujo 'centro' consistia num núcleo interior, que permanecia o mesmo ao longa da existência do indivíduo" (HALL, 2014, p. 11) Isso quer dizer que o centro essencial do "eu" era a identidade de uma pessoa, dotada de capacidades de razão, de consciência e de ação. Não se tinha em mente, porém, todos os aspectos fora do sujeito que o condicionavam e formavam o seu modo de estar-no-mundo. Neste sentido, Peter Berger (1995, p. 
96) dirá que "a posição social básica de um indivíduo é determinada ao nascimento. Pelo menos em teoria ele não tem absolutamente nenhuma possibilidade de modificar essa posição no decorrer de sua vida." Todavia, essa foi justamente a reviravolta na pós-modernidade.

O sujeito sociológico, por sua vez, refletia a crescente complexidade do mudo moderno e a consciência de que esse núcleo interior do sujeito não era autônomo e autossuficiente, mas era formado na relação com outras pessoas, que mediavam outros valores, interesses e visões de mundo onde o sujeito habitava. Com outras palavras, a identidade desse sujeito era formada a partir da interação entre o eu e a sociedade.

Isso nos faz lembrar que a condição humana é condicionada ao meio onde se desenvolve, cresce e morre. Outro fator interessante nessa perspectiva do sujeito sociológico é que "a identidade, então, costura o sujeito à estrutura. Estabiliza tanto os sujeitos quanto os mundos culturais que eles habitam, tornando ambos reciprocamente mais unificados e previsíveis" (HALL, 2014, p. 11).

O que vivenciamos, agora, na pós-modernidade é justamente a mudança desses paradigmas. O sujeito que até então havia uma identidade unificada e estável, está se tornando cada vez mais fragmentado, composto não mais de uma, mas de múltiplas identidades. Hall nos diz que:

Correspondentemente, as identidades, que compunham as paisagens sociais 'lá fora' e asseguravam a nossa conformidade subjetiva com as 'necessidades' objetivas da cultura, estão entrando em colapso, como resultado de mudanças estruturais e institucionais. $\mathrm{O}$ próprio processo de identificação, através do qual nos projetamos em nossas identidades culturais, tornou-se mais provisório, variável e problemático. (HALL, 2014, p.11)

Todo esse processo produzirá o que Stuart Hall chama de "sujeito pós-moderno", onde esse assume não uma, mas diferentes identidades em momentos diversos, ou seja, identidades que não são unificadas ao redor de um "eu" coerente, como vimos anteriormente.

Sendo assim, a identidade não é definida biologicamente, mas sim historicamente, formada e transformada continuamente em relação às maneiras pelas quais somos representados e interpelados pelas culturas que nos rodeiam. "A sociedade confere ao indivíduo não só o conjunto de papéis mas também uma identidade designada" (BERGER, 2004, p. 27).

Agora a identidade tida como plenamente unificada, completa, segura e coerente é uma mera fantasia. Tudo isso, como vimos anteriormente, causou a grande, delicada e dilacerante "crise 
de identidade", que ainda está em processo de desenvolvimento, principalmente para nós ocidentais.

À medida que os sistemas de significação e representação cultural se multiplicam, "somos confrontados por uma multiplicidade desconcertante e cambiante de identidades possíveis, com as quais poderíamos nos identificar a cada uma delas - ao menos temporariamente" (cf. HALL, 2014, p. 12).

O caráter da mudança de identidade na pós-modernidade não é apenas um rompimento, uma descontinuidade ou um deslocamento, mas um processo sem fim de rupturas e fragmentações internas em seu próprio interior. Com outras palavras, a sociedade atual não possui um único referencial de verdade, um centro no qual se espelhar ou um único princípio para se nortear. E quais são as consequências imediatas dessas metamorfoses? Uma das principais consequências é que as sociedades modernas são caracterizadas pela "diferença" e pela "diversidade". Por esta razão se faz necessária uma verdadeira educação que realmente eduque para as peculiaridades e riquezas da tolerância e da diversidade cultural.

Uma vez que o sujeito pós-moderno vive em constates transformações, podemos ter exemplos dessas mudanças dentro da filosofia e da literatura através da obra de dois relevantes pensadores: Friedrich Nietzsche e Lewis Carroll.

Rebelde e provocador, o alemão Nietzsche ${ }^{3}$ se propôs a desmascarar as fundações da cultura ocidental, mostrando que há interesses e motivações ocultas, e não valores absolutos, em conceitos como verdade, bem e mal. Com isso, Nietzsche trouxe uma nova interpretação dos sistemas filosóficos, morais e religiosos. Sua frase mais conhecida, "Deus está morto", não se refere ao ateísmo, mas nos fala da necessidade de romper com a "moral de rebanho" (as verdades tidas como inquestionáveis e o que é aceito por imposição) para viver as potencialidades humanas em sua plenitude. Por meio da obra "Genealogia da Moral", Nietzsche acreditava ser preciso investigar a

\footnotetext{
${ }^{3}$ Friedrich Nietzsche nasceu em 15 de outubro de 1844, em Rökken (Prússia, atual Alemanha). Criado em uma família de clérigos luteranos, Nietzsche foi preparado para ser pastor. Aos 18 anos, perdeu a fé em Deus e passou por um período libertino, quando contraiu sífilis. Nietzsche tornou-se professor de filosofia e poesia gregas com apenas 24 anos, na Universidade de Basileia, em 1869. Abandonou a universidade em 1879. Sofrendo de intensas dores de cabeça e de uma crescente deterioração da vista, levou uma vida solitária, vagando entre a Itália, os Alpes suíços e a Riviera Francesa - ele atribui à doença o poder de lhe conferir uma clarividência e lucidez superiores. Em janeiro de 1889, ao ver um cocheiro chicoteando um cavalo, abraçou o pescoço do animal para protegê-lo e caiu no chão. Havia enlouquecido? Muitos amigos que visitavam Nietzsche na clínica psiquiátrica duvidavam de sua doença e alguns de seus biógrafos afirmam que, longe de loucura, ele atingiu uma enorme sanidade. O filósofo morreu em 1900.
} 
origem dos valores, em vez de simplesmente aceitá-los (cf. NICOLA, 2005, p. 405-419).

Em seu livro, "Assim falou Zaratustra", Nietzsche nos deixa ver três metamorfoses do espírito que cada indivíduo deve enfrentar para vir-a-ser-quem-é. Eis parte do texto na íntegra, para não perder a sua força:

Três metamorfoses do espírito menciono para vós: de como o espírito se torna camelo, o camelo se torna leão e o leão, por fim, criança. Há muitas coisas pesadas para o espírito, para o forte, resistente espírito em que habita a reverência: sua força requer o pesado, o mais pesado. O que é pesado? Assim pergunta o espírito resistente, e se ajoelha, como um camelo, e quer ser bem carregado. O que é o mais pesado, ó heróis?, pergunta o espírito resistente, para que eu o tome sobre mim e me alegre de minha força. Não é isso: rebaixarse, a fim de machucar sua altivez? Fazer brilhar sua tolice, para zombar de sua sabedoria? Ou é isso: deixar nossa causa quando ela festeja seu triunfo? Subir a altos montes, a fim de tentar o tentador? Ou é isso: alimentar-se das bolotas e da erva do conhecimento e pela verdade padecer fome na alma? Ou é isso: estar doente e mandar para casa os consoladores e fazer amizade com os surdos, que nunca ouvem o que queres? Ou é isso: entrar em água suja, se for a água da verdade, e não afastar de si as frias rãs e os quentes sapos? Ou é isso: amar aqueles que nos desprezam e estender a mão ao fantasma, quando ele quer nos fazer sentir medo? Todas essas coisas mais que pesadas o espírito resistente toma sobre si: semelhante ao camelo que ruma carregado para o deserto, assim ruma ele para seu deserto. Mas no mais solitário deserto acontece a segunda metamorfose: o espírito se torna leão, quer capturar a liberdade e ser senhor em seu próprio deserto. Ali procura o seu derradeiro senhor: quer se tornar seu inimigo e derradeiro deus, quer lutar e vencer o grande dragão. Qual é o grande dragão, que o espírito não deseja chamar de senhor e deus? "Não-farás" chama-se o grande dragão. Mas o espírito do leão diz "Eu quero". "Não-farás" está no seu caminho, reluzindo em ouro, um animal de escamas, e em cada escama brilha um dourado "Não-farás!". Valores milenares brilham nessas escamas, e assim fala o mais poderoso dos dragões: "Todo o valor das coisas brilha em mim". "Todo o valor já foi criado, e todo o valor criado - sou eu. Em verdade, não deve mais haver 'Eu quero'!" Assim fala o dragão. Meus irmãos, para que é necessário o leão no espírito? Por que não basta o animal de carga, que renuncia e é reverente? Criar novos valores - tampouco o leão pode fazer isso; mas criar a liberdade para nova criação - isso está no poder do leão. Criar liberdade para si e um sagrado "Não" também ante o dever: para isso, meus irmãos, é necessário o leão. Adquirir o direito a novos valores - eis a mais terrível aquisição para um espírito resistente e reverente. Em verdade, é para ele uma rapina e coisa de um animal de rapina. Ele amou outrora, como o que lhe era mais sagrado, o "Tu-deves"; agora tem de achar delírio e arbítrio até mesmo no mais sagrado, de modo a capturar a liberdade em relação a seu amor: é necessário o leão para essa captura. Mas dizei-me, irmãos, que pode fazer a criança, que nem o leão pôde fazer? Por que o leão rapace ainda tem de se tornar criança? Inocência é a criança, e esquecimento; um novo começo, um jogo, uma roda a girar por si mesma, um primeiro movimento, um sagrado dizer sim. Sim, para o jogo da criação, meus irmãos, é preciso um sagrado dizer sim: o espírito quer agora sua vontade, o perdido para o mundo conquista seu mundo. Três metamorfoses do espírito eu vos mencionei: como o espírito se tornou camelo, o camelo se tornou leão e o leão, por fim, criança. (NIETZSCHE, 2008, p. 37-38)

Para Nietzsche, uma verdadeira educação seria a existencial, o melhor meio para se preparar 
para a cultura e formar uma identidade cultural sólida sem preconceitos e aberta à diversidade, e isso ainda na fase da juventude. Para ele um jovem consiste em um conjunto de forças singulares, onde engrandecer o foco em torno do qual uma individualidade do sujeito se organiza. O jovem deve compreender, através da educação, o sentido da liberdade de modo absolutamente diferente e não mais um livre-arbítrio para fazer tudo o que lhe convir. Neste sentido, liberdade, então, é exercida pelos desígnios da natureza e da natureza ninguém se liberta. Sendo assim, o ser humano requer uma entrega absoluta à tarefa da cultura. Duas forças entram em cena: a própria natureza e uma cultura que favoreça ou não o seu aperfeiçoamento de realização e liberdade (cf. COSTA, 2007, p. 139-148).

Agora, vejamos na literatura do paradoxo de Lewis Carroll ${ }^{4}$ sinais de premonição das grandes rupturas que se sucederam no século XX em diante. É notório que cada fase histórica tem uma literatura que reflete a condição do ser humano e de seu contexto, e no caso em questão, o período é vitoriano (período do reinado da rainha Vitória, em meados do século XIX, de junho de 1837 a janeiro de 1901), na Inglaterra. E a literatura dessa época é quase sempre realística e moralista. Concomitantemente, porém, nasceu o desejo de representar conteúdos diversos daqueles reais, e justamente nesta direção, com o pseudônimo de Lewis Carroll, que Charles Lutwidge Dodgson, tímido e reservado reverendo e professor de matemática de extraordinária conduta, tipicamente vitoriana, escreveu "Alice no País das Maravilhas".

A sociedade de Carroll é tão efêmera e vazia quanto uma esfera de cristal, e por isso ele decidiu rompê-la, descobrir o que havia dentro, desmascarar o falso bom senso burguês. Ao respeito, à seriedade e à firmeza da sociedade, o autor opõe um país onde reina o não respeito, o jogo, a festa, a instabilidade, como se ele fosse um apóstolo do niilismo e do existencialismo. $\mathrm{O}$ país das maravilhas parece ser um lugar onde se busca desfragmentar a realidade, reduzi-la ao nada, e isso reflete perfeitamente o sentido de diluição que permeia a literatura dos últimos cem anos, ou seja, a perda de confiança com a realidade, a necessidade de desmontá-la, contrapondo mundos

\footnotetext{
${ }^{4} \mathrm{O}$ verdadeiro nome de Lewis Carroll era Charles Lutwidge Dogson (1832 - 1898) foi um poeta, matemático e romancista britânico. Foi também diácono da Igreja Anglicana. Carroll tornou-se mundialmente famoso quando escreveu o clássico livro "Alice no País das Maravilhas", e além de outros poemas. Carroll ingressou na Universidade de Oxford, e sempre se mostrou bastante interessado e esforçado, chegando a ganhar uma medalha de honra ao mérito. Devido ao seu desempenho como matemático, foi convidado a lecionar matemática no Christ College, em Oxford. Lewis Carroll era apaixonado por jogos, tanto que inventou um grande número de enigmas, jogos matemáticos e de lógica e por isso, os livros infantis de Carroll contêm diversos problemas matemáticos e de lógica.
} 
irreais nos quais se refugiar no nonsense (cf. IRWIN, 2010, p. 24-30).

Será justamente essa falta de sentido um dos sintomas mais evidentes da identidade do sujeito pós-moderno, como havíamos mostrado. Uma passagem elucidativa na obra de Lewis nos confirma isso, quando Alice questiona o Gato para saber aonde ir:

'Bichano de Cheshire', começou, muito tímida, pois não estava nada certa de que esse nome iria agradá-lo; mas ele só abriu um pouco mais o sorriso. 'Bom, até agora ele está satisfeito', pensou e continuou: 'Poderia me dizer, por favor, que caminho devo tomar para ir embora daqui?' 'Depende bastante de para onde quer ir', respondeu o Gato. 'Não me importa muito para onde', disse Alice. 'Então não importa que caminho tome', disse o gato. 'Contanto que eu chegue a algum lugar', Alice acrescentou à guisa de explicação. 'Oh, isso você certamente vai conseguir', afirmou o Gato, 'desde que ande o bastante'. (CARROLL, 2009, p. 76-77)

De fato, a sociedade atual, assim chamada pós-moderna, deve, ainda, andar muito para alcançar uma identidade que seja capaz de lidar com a diferença e a diversidade. Nos falta uma educação voltada para a tolerância e a solidariedade. Se as novas gerações nascem em meio às tempestades do mar aberto de uma modernidade líquida, para usar a expressão de Zygmunt Bauman (2012, p. 44-69) no livro "Ensaios sobre o conceito de cultura", se faz necessário um farol potente para guiar e iluminar a conjunção entre cultura e identidade, através de uma nova percepção da realidade e uma nova construção semântica a ser utilizada na educação das novas gerações. É o que pincelaremos a seguir.

\section{Reencantar a educação para reeducar o mundo através de uma sensibilidade solidária}

Antes de refletirmos sobre solidariedade, precisamos falar sobre a exclusão social e a sua principal causa. É oportuno dizer que estamos inseridos dentro de um sistema capitalista, num mercado de consumo assustador, que, com o auxílio do mass media, tem criado necessidades profundas de consumo nas várias camadas sociais, e que, por sua vez, nem todas as pessoas têm os recursos suficientes para terem acesso a vários bens de consumo. Por isso, nem todo desejo de consumo é realizado e o acesso básico para se ter uma vida digna, dentro desse sistema, é altamente comprometido. E, de novo, os mais prejudicados são os pobres. Além disso, "o desemprego estrutural é, sem dúvida, um dos problemas fundamentais da nossa época, além de ser uma das 
causas principais da exclusão social.” (cf. ASSMANN; MO SUNG, 2001. p.91) ${ }^{5}$

De acordo com Assmann e Mo Sung, a cultura na qual vivemos traz consigo uma visão fragmentada da realidade. Fazendo com que não percebamos a interdependência como um fato, ou seja, a preocupação com o outro, o cuidado que devemos ter com nossas ações que afetam direta e indiretamente as outras pessoas (o sentir empatia e a compaixão para com o sofrimento das pessoas que vivem conosco neste planeta).

Toda a preocupação com o outro está ofuscada, em nossa sociedade, comandada pelas políticas neoliberais. Sendo assim, esses autores nos alertam para termos uma educação voltada para a solidariedade, que nos faça perceber o sistema excludente em que vivemos. E os autores nos direcionam para uma visão sistêmica, para que tenhamos uma humanidade que reconheça seus semelhantes, e, assim, mobilize as pessoas em favor dos excluídos.

Sendo assim, é fundamental que modifiquemos, também, a maneira de compreender e ensinar ciências/disciplinas que compõem o currículo escolar, repensar o próprio papel social do ambiente escolar e da formação dos docentes.

Retornando à escola, para que tenhamos uma educação que seja verdadeiramente crítica, humanizadora e que (sem distinção) abarque a todos, é imprescindível que os educadores também sejam bem formados e que busquem formação continuada no que se refere aos vários tipos de discriminação que ocorrem dentro no ambiente escolar, pois a escola não pode, de maneira alguma, trabalhar com a naturalização de preconceitos. Cada instituição escolar tem a obrigação de lutar contra todo tipo de intolerância, porém, seus educadores devem compreender, de verdade, a relevância de tal tarefa. (RODRIGUES, 2017, p. 699)

Neste sentido podemos compreender que a sensibilidade solidária gera o desejo de um horizonte utópico e cheio de esperança. Esta, por seu turno, dá sentido à sensibilidade solidária que realimentará o anseio de um mundo mais humano e acolhedor. E isto se dará por meio de uma sociedade mais justa e, logicamente, mais solidária. Substituindo, assim, a competição pela cooperação no campo econômico partilhando. Dessa forma, os frutos do trabalho. Paulo Freire nos

\footnotetext{
${ }^{5}$ Assmann e Mo Sung exploram muito bem o tema solidariedade e a educação como dois grandes braços para um mundo menos excludente, pois, para eles, ainda é possível revertermos este quadro de desesperança e este abismo de exclusão no qual estamos sujeitos a cair. Entre as tantas propostas que eles nos apresentam, uma delas é a reorganização do modo de aprender, viver, conviver e o modo de ver o outro, criando assim, uma identidade cultural fundamentada na tolerância e no respeito à diversidade. E isso se dará por meio de uma educação voltada para a solidariedade e a esperança.
} 
informa que ensinar exige acreditar na esperança:

\begin{abstract}
A esperança faz parte da natureza humana. Seria uma contradição se, inacabado e consciente do inacabamento, primeiro, o ser humano não se inscrevesse ou não se achasse predisposto a participar de um movimento constante de busca e, segundo, se buscasse sem esperança. A desesperança é negação da esperança. A esperança é uma espécie de ímpeto natural possível e necessário, a desesperança é o aborto deste ímpeto. A esperança é um condimento indispensável à experiência histórica. Sem ela, não haveria História, mas puro determinismo. (FREIRE, 1997, p. 80-81)
\end{abstract}

Também, é necessário traduzir a sensibilidade solidária em políticas econômicas, sociais e eficazes gerando uma rede de colaboração solidária. Enfim, entre o desejo do novo que nasce da sensibilidade solidária e a institucionalização da solidariedade na sociedade existe uma relação complexa e contraditória. Será impossível assumir a solidariedade como um valor social, sem termos uma educação baseada no pensamento complexo, para, assim, não haver um enfraquecimento da responsabilidade de um para com os outros. Afinal de contas, o ser humano é um ser complexo como também é a sociedade e o meio no qual vivemos.

Contudo, devemos lutar por uma ética de responsabilidade solidária, onde a caridade seja o instrumento para o fim da exclusão. Todavia, como foi acenado, hoje a situação é crítica, pois muitos, em nome da liberdade e da autonomia pessoal, acham-se no direito de se preocuparem apenas consigo mesmos e isso se torna um empecilho para a solidariedade. Pois como pode alguém ajudar outros se não consegue olhá-los? Como querer ajudar sem sentir o desejo para tal? É contra essa correnteza que todas as "pessoas de boa vontade" deveriam nadar. E isso só acontecerá a partir do momento em que as pessoas tomarem consciência da presença e da necessidade do outro para viverem e serem quem são.

Mas só isso não basta. Retornaremos agora para o tema da necessidade de uma educação voltada para a esperança. Vemos que tal educação será a base para conseguirmos uma sociedade mais preocupada com a pessoa do outro. Podemos observar que a simples convivência dentro de uma sala de aula e a relação entre docente e discente são importantes e fundamentais. Isso porque somos seres afetivos, e o fato de sabermos que somos amados, e que há realmente alguém preocupado conosco, gera, em nós, o desejo de retribuir o mesmo carinho e atenção. Pois, todo aquele que se sente amado é "condenado" a também amar. E esse desejo de amar e ser amado é uma das chaves para termos uma sociedade mais solidária e fraterna. 
Nesse caminho, se a literatura parte da realidade para o papel, devemos agora traçar o caminho inverso. Com isso, também, não podemos nos esquecer que a sensibilidade solidária não está desvinculada das competências sociais e técnicas, pois o novo mundo solidário dar-se-á dentro do sistema no qual estamos vivendo. Substituindo a competitividade pela cooperação numa grande rede solidária.

\section{Considerações finais}

Vale ressaltarmos que os autores ao tratarem do tema "solidariedade", apoiam-se em insignes pensadores hodiernos: Edgar Morin ${ }^{6}$, João Batista Libâneo ${ }^{7}$, Paulo Freire ${ }^{8}$ e Philippe Perrenoud ${ }^{9}$. Eles, no conjunto de suas obras nos fazem enxergar novos horizontes e acender uma chama de esperança, de que é possível, por meio da educação e do reconhecimento da importância do outro, alcançar uma identidade cultural sensibilizada, tolerante e mais humana com relação às diferenças e diversidades.

Também, é urgente a necessidade de uma nova revolução no modo de conhecer, aprender, pensar, viver, sentir e ver o mundo, o outro e a si mesmo. Para que as novas gerações consigam engendrar uma educação cultural onde o ser humano possa vir-a-ser quem é em um ambiente mais sensível, amável e acolhedor.

Nesse sentido, o ambiente escolar se faz espaço importantíssimo no processo de reeducação dos estudantes para a valorização das pessoas, de seus saberes, de seus fazeres, de suas identidades

\footnotetext{
${ }^{6}$ No seu livro, “A cabeça bem-feita”, Edgar Morin, grande pedagogo de nossa contemporaneidade, nos traz uma séria proposta de reformar o ensino e reformar o ensino para reformar o pensamento. Uma das palavras-chave é a "transdiciplinariedade" defendida por Edgar. Pois a falta de "relação" entre os diversos conhecimentos, fazem que tenhamos uma sociedade fechada e o "complexo de vida real" repartido. Por isso a necessidade de uma cabeça bemfeita que proporcione a organização entre os conhecimentos, facilite o ensino da condição humana, que melhore o modo de vida e traga força para lidar com as incertezas e dar uma justa educação cidadã.

${ }^{7}$ No seu livro, "A Arte de Formar-se", Libâneo quis caracterizar a própria formação como uma arte. Pois esta evolui, transforma-se a todo o momento, ou seja, possuindo uma verdadeira plasticidade. $\mathrm{O}$ autor ainda nos oferece cinco pilares trabalhados em cinco capítulos, que são, respectivamente: Aprender a conhecer e a pensar; Aprender a fazer; Aprender a viver juntos, a viver com os outros; Aprender a ser e Aprender a discernir a vontade de Deus. À medida que o homem aprende a ser, ele acaba percebendo que faz parte de um projeto que está acima dele. Este projeto é o de Deus. Ter a capacidade de discernir a vontade Dele é ter a "chave" da liberdade, tornando o homem o próprio sujeito de sua formação para "ser mais" no auxílio dos mais fracos.

${ }^{8} \mathrm{Na}$ "Pedagogia do Oprimido", aprendemos que cada um deve ser sujeito de sua própria formação, tornando-se consciente dos verdadeiros valores que são necessários para se ter uma vida digna sem exclusão.

${ }^{9}$ Nas "10 Novas Competências para Ensinar" o autor mobilizar um conjunto de recursos cognitivos, ou seja, saberes, capacidades, informações etc., para solucionar uma série de situações que aparecerão durante o processo de ensinoaprendizagem.
} 
e de suas culturas. Ainda, o respeito e a tolerância se colocam como instrumentos sensíveis de aprendizagem em relação a tudo que diz respeito ao outro e a si mesmo. E, como últimas considerações, podemos verificar que a sensibilidade solidária é um ato de inteligência em relação à compreensão das estruturas neoliberais que nos prendem, de aceitação ao mundo da cooperação e de abertura aos conhecimentos do "outro".

\section{Referências}

ASSMANN, Hugo; MO SUNG, Jung. Competência e sensibilidade solidárias. 2. ed. Petrópolis: Vozes, 2001.

BAUMAN, Zygmunt. Ensaios sobre o conceito de cultura. Rio de Janeiro: Zahar, 2012.

BENTO XVI. Carta encíclica Deus Caritas Est (25 de dezembro de 2006), n.25. $3^{\text {a }}$ ed. São Paulo: Paulinas, 2006.

BERGER, Peter Ludwig. $O$ dossel sagrado - Elementos para uma teoria sociológica da religião. 5. ed. São Paulo: Paulus, 2004.

BERGER, Peter Ludwig. Perspectivas sociológicas. 15ª ed. Petrópolis: Vozes, 1995.

CARROLL, Lewis. Aventuras de Alice no país das maravilhas. Através do espelho e o que Alice encontrou por lá. Rio de Janeiro: Zahar, 2009.

COSTA, Affonso Henrique Vieira da (Org.). Manual de iniciação à filosofia. $2^{\mathrm{a}}$ ed. Petrópolis: Vozes, 2007.

FREIRE, Paulo. Pedagogia da autonomia. 5a ed. Rio de Janeiro: Paz e Terra, 1997.

FREIRE, Paulo. Pedagogia do oprimido. 2ª ed. Rio de Janeiro: Paz e Terra, 1975.

HALL, Stuart. A identidade cultural na pós-modernidade. Rio de Janeiro: Lamparina, 2014.

HALL, Stuart. Da diáspora: identidades e mediações culturais. Belo Horizonte: Editora UFMG, 2009, p. 43.

IRWIN, William (Org.). Alice no país das maravilhas e a filosofia: cada vez mais e mais curioso. São Paulo: Madras, 2010.

LIBANEO, João Batista. A arte de formar-se. São Paulo: Loyola, 2001.

MORIN, Edgar. A cabeça Bem-Feita: repensar a reforma, reformar o pensamento. $8^{\text {a }}$ ed. Rio de Janeiro: Bertrand Brasil, 2003. 
NICOLA, Ubaldo. Antologia ilustrada de filosofia: das origens à idade moderna. São Paulo: Editora Globo, 2005.

NIETZSCHE, Friedrich. Assim falou Zaratustra. $2^{\text {a }}$ ed. São Paulo: Martin Claret, 2008.

PERRENOUD, Philippe. 10 Novas Competências para Ensinar. Porto Alegre: Artes Médicas Sul, 2000.

RODRIGUES, Walace. Destruindo discursos de diferença na escola. Educação \& Realidade, Porto Alegre, v. 42, n. 2, p. 687-706, abr./jun. 2017.

TAVARES, Sinivaldo Silva. Da autonomia do indivíduo à responsabilidade solidária. Revista Eclesiástica Brasileira, Petrópolis, julho 2007.

Recebido em 31 de janeiro de 2018. Aceito em 08 de outubro de 2018. 